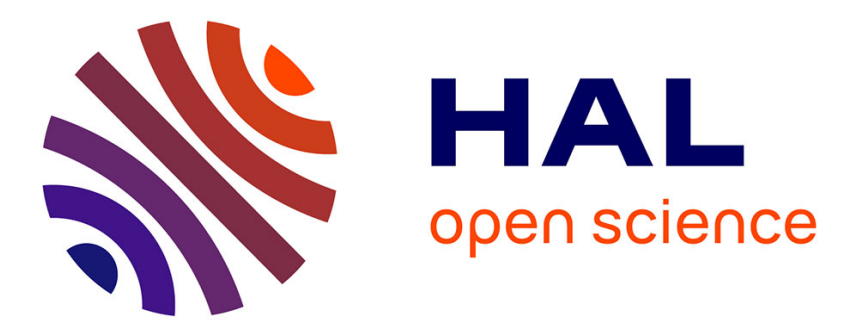

\title{
Manganese phosphinocarbodithioate for RAFT polymerisation with sunlight-induced chain end post-treatment
}

Ihor Kulai, Andrii Karpus, Liubov Soroka, Dmitry A. Valyaev, Valérie Bourdon, Eric Manoury, Rinaldo Poli, Mathias Destarac, Stéphane Mazières

\section{To cite this version:}

Ihor Kulai, Andrii Karpus, Liubov Soroka, Dmitry A. Valyaev, Valérie Bourdon, et al.. Manganese phosphinocarbodithioate for RAFT polymerisation with sunlight-induced chain end post-treatment. Polymer Chemistry, 2019, 10 (2), pp.267-277. 10.1039/c8py01279b . hal-02134244

\author{
HAL Id: hal-02134244 \\ https://hal.science/hal-02134244
}

Submitted on 17 Nov 2020

HAL is a multi-disciplinary open access archive for the deposit and dissemination of scientific research documents, whether they are published or not. The documents may come from teaching and research institutions in France or abroad, or from public or private research centers.
L'archive ouverte pluridisciplinaire HAL, est destinée au dépôt et à la diffusion de documents scientifiques de niveau recherche, publiés ou non, émanant des établissements d'enseignement et de recherche français ou étrangers, des laboratoires publics ou privés. 


\section{Journal Name}

\section{ARTICLE}

\section{Manganese Phosphinocarbodithioate for RAFT Polymerization with Sunlight-Induced Chain End Post-Treatment}

\begin{abstract}
02190219Received 00th January
\end{abstract} 20xx,

Accepted 00th January 20xx

DOI: $10.1039 / x 0 x \times 00000 x$

www.rsc.org/

\author{
Ihor Kulai, ${ }^{a}$ Andrii Karpus, ${ }^{a, b}$ Liubov Soroka, ${ }^{a, b}$ Dmitry A. Valyaev, ${ }^{b}$ Valérie Bourdon, ${ }^{c}$ Eric Manoury, ${ }^{* b}$ \\ Rinaldo Poli, ${ }^{b}$ Mathias Destarac ${ }^{* a}$ and Stéphane Mazières ${ }^{* a}$
}

A new manganese RAFT agent of formula $\mathrm{Cp}(\mathrm{CO})_{2} \mathrm{MnP}(\mathrm{Ph})_{2} \mathrm{C}(=\mathrm{S}) \mathrm{SCH}\left(\mathrm{CH}_{3}\right) \mathrm{Ph}$ was synthesized in a good overall yield by a three-step reaction from cymantrene and diphenylphosphine as main starting materials. This complex was proved to be efficient for the control of RAFT polymerisation of St, $n$-BA and DMAA. The reaction course can be conveniently monitored by ${ }^{31} \mathrm{P}$ NMR spectroscopy. The controlled character of these polymerisations and the integrity of the polymer chain ends were exemplified by the synthesis of diblock copolymers of St and $n$-BA. In the case of long polymerisation times (i.e. PSt), photo-induced polymer chain coupling reactions were detected. Importantly, removal of the Mn-RAFT- $\omega$-chain end by visible light irradiation led to the formation of a monomodal SH-terminated PSt. These phenomena were evidenced by IR spectroscopy, SEC with RI and UV detection modes and by ESI mass spectrometry.

\section{Introduction}

After two decades of active research in reversibledeactivation radical polymerisations (RDRP), reversible addition-fragmentation chain transfer (RAFT) polymerisation ${ }^{1}$ is now established as a very robust and versatile process for the preparation of precisely controlled polymers in terms of molar mass, dispersity, end-functionality and architecture. The RAFT process involves reversible chain transfer agents (CTA) of general formula $\mathrm{Z}(\mathrm{C}=\mathrm{S}) \mathrm{SR}$ that control the radical polymerisation of a large spectrum of vinyl monomers. The key role of the $R$ and $Z$ groups in the setting of a fast and efficient addition-fragmentation equilibrium during polymerisation is now well understood and largely documented. ${ }^{2-4}$ In particular, after extensive studies of the structure-reactivity relationship on the main classes of RAFT agents (namely dithioesters, ${ }^{5}$ trithiocarbonates, ${ }^{2}$ dithiocarbamates ${ }^{6,7}$ and $x^{2}$ anthates ${ }^{2,8,9}$ ), it can be concluded that combinations of more activated monomers (MAMs) and less activated monomers (LAMs) in block copolymers are scarce and the reported strategies lack simplicity and versatility. There are few isolated exceptions like $N$-methyl- $N$-(4-pyridinyl) $)^{10,11}$ or $\quad \mathrm{N}$-aryl- $N$-(4-pyridinyl) $)^{12}$ dithiocarbamate switchable RAFT agents, the reactivity of which is changed by reversible (de)protonation by a strong acid (base) to control successively MAM and LAM polymerisations.

a. Laboratoire des IMRCP, Université Paul Sabatier, CNRS UMR 5623, 118 route de Narbonne 31062 Toulouse, France.

b. CNRS, LCC (Laboratoire de Chimie de Coordination), Université de Toulouse, UPS, INPT, 205 Route de Narbonne, BP 44099, 31077 Toulouse, France.

c. ICT - Service de spectrométrie de masse - Université Paul Sabatier 118, Route de Narbonne - 31062 Toulouse, France.

+ Electronic Supplementary Information (ESI) available: experimental details. See DOI: $10.1039 / x 0 x \times 00000 x$
Another strategy consists in the selection of a RAFT agent of intermediate reactivity. Recently, the CSIRO group designed dithiocarbamate RAFT agents comprising 3,5-dimethylpyrazole $Z$ groups which allowed the synthesis of low $€$ PDMA- $b$-PVAc copolymers without a need to switch the CTA reactivity, ${ }^{13}$ but led to poor control for MMA. The introduction of a chlorine or a bromine atom at the 4-position on the pyrazole ring ${ }^{14}$ slightly improved the control of MMA polymerisation, but significantly retarded the polymerisation of vinyl acetate (VAc) with limited conversions. More conventional RAFT agents of intermediate reactivity, e.g. $O$-ethyl xanthates ${ }^{15}$ or $N, N$-diphenyl dithiocarbamate ${ }^{16}$ allow a moderate control for some MAMs (control of number-average molar mass $M_{\mathrm{n}}$ and relatively high dispersity $\oslash$ for styrene (St), ${ }^{16}$ acrylates ${ }^{17}$ and acrylamides $)^{18}$ and much better control for LAMs. Therefore, the identification of original classes of RAFT agents, likely to cover a broad spectrum of monomer reactivity, remains topical and highly challenging. Recently, we identified a new class of triarylstannanecarbodithioate RAFT agents with a tin atom connected to the $\mathrm{C}=\mathrm{S}$ bond. ${ }^{19,20}$ The bulky and strongly electropositive tin atom confers high reactivity on Sn-RAFT agents in St and $n$-butyl acrylate ( $n$-BA) polymerisations, but at the same time they inhibit the polymerisation of LAMs.

The presence of phosphorus in the $\mathrm{Z}$ group of RAFT agents has attracted little attention. Some of us $^{9}$ reported that phosphonate associated with a fluorinated group in the alkoxy part of a xanthate disfavours the conjugation of the oxygen atom and enhances the reactivity of the carbon-sulfur double bond. Another class of RAFT agents bears a phosphorus atom at the $\alpha$-position of the thiocarbonylthio group. First detailed studies concerned phosphoryl and (thiophosphoryl)dithioformates ${ }^{21,22}$ of general formula RS- $(C=S)-P(X)\left(O R^{\prime}\right)_{2}(X=$ $O, S$, respectively). However their behaviour in the 

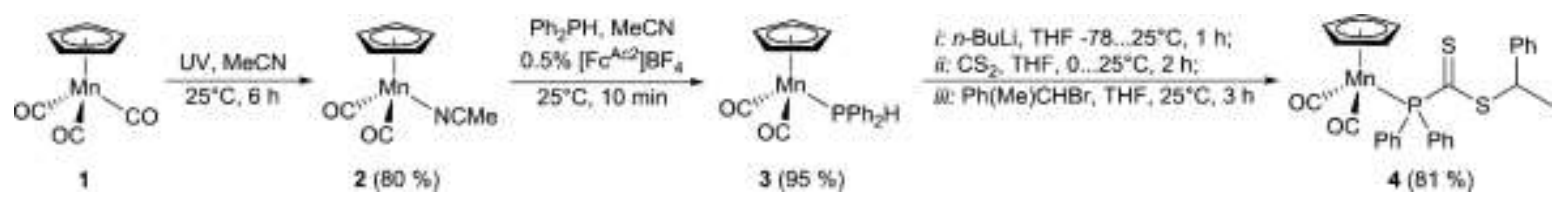

Scheme 1. Synthesis of Mn-RAFT agent 4.

polymerisation of St, leading to uncontrolled $M_{\mathrm{n}}$ values with $\oslash$ greater than 2, was not conclusive and suggested the contribution of side reactions. Later, we reported the synthesis and RAFT polymerisation behaviour of phosphinoyl- and thiophosphinoylcarbodithioates $R S-(C=S)-P(X)\left(R^{\prime}\right)_{2}(X=O, S$, respectively). ${ }^{23}$ In contrast with dithioformate counterparts, the polymerisation proceeded in a controlled fashion for St and $n$ BA, but again not for LAMs. We have also shown that organometallic derivatives of diphenylphosphinocarbodithioates $(\mathrm{CO})_{5} \mathrm{M}\left(\mathrm{Ph}_{2}\right) \mathrm{P}-(\mathrm{C}=\mathrm{S})-\mathrm{SR}(\mathrm{M}=\mathrm{Cr}, \mathrm{Mo}, \mathrm{W})$ behave as efficient mediators for the RAFT polymerisation of St and $n$-BA. ${ }^{24}$

The presence of a terminal labile $-(C=S) Z$ group, which is likely to degrade over time and generate small sulfur-containing compounds, is the Achilles heel of the RAFT process from the standpoint of its industrial viability. ${ }^{25}$ Hence, the identification of simple, inexpensive and quantitative methods for removal of the Z-group of RAFT polymers ${ }^{26}$ remains a highly important topic.

There is currently a growing interest in light-mediated RAFT processes ${ }^{27-30}$ and chain-end transformation. ${ }^{31}$ One manganese complex, $\mathrm{Mn}_{2}(\mathrm{CO})_{10}$, has been reported as photoinitiator for RAFT polymerization, ${ }^{32}$ and we propose here a manganese phosphinocarbodithioate derivative 4 (Scheme 1), namely $\mathrm{Mn}$ RAFT, that is capable of mediating RAFT polymerisation under thermal initiation before fast and quantitative cleavage of the terminal RAFT group induced by visible light, to yield thiolterminated polymers.

\section{Results and Discussion}

Compound 4 was selected as a potential manganesecontaining RAFT agent because of the availability and the stability of manganese(I) cyclopentadienyldicarbonylphosphine complexes under ambient conditions. Inspired by the efficient synthesis of chromium and molybdenum containing RAFT agents, ${ }^{24}$ we imagined that 4 could be obtained by a deprotonation / alkylation sequence from $\mathbf{3}$ (see Scheme 1). Compound 3 has already been synthesized in 56\% overall yield by the reaction of $\mathrm{Cp}(\mathrm{CO})_{2} \mathrm{Mn}(\mathrm{THF})$, which is typically photochemically generated at low temperature, with potassium phosphide $\mathrm{Ph}_{2} \mathrm{PK}$ (dioxane) ${ }_{2}$ followed by protonation with acetic acid. ${ }^{33}$ Since this procedure required a large amount of THF, long photolysis time at low temperature, and handling of extremely air and moisture sensitive phosphide and manganese complexes, we decided to search for a more convenient preparation of $\mathbf{3}$ from industrially produced cymantrene $\mathbf{1}$ and diphenylphosphine (Scheme 1). First, a well-known direct photochemical substitution of one carbonyl ligand in cymantrene with phosphine was attempted. ${ }^{34-38}$ However, under the conditions previously optimized for $\mathrm{PPh}_{3}{ }^{38}$ the reaction selectivity was quite low and a tedious chromatographic purification was necessary to remove starting cymantrene and double substitution product $\mathrm{Cp}(\mathrm{CO}) \mathrm{Mn}\left(\mathrm{PPh}_{2} \mathrm{H}\right)_{2}$ to provide the desired complex 3 only in $c a$. $50 \%$ yield.

Inspired by the work of Kochi on the oxidatively induced acetonitrile substitution in $\mathrm{Cp}^{\prime}(\mathrm{CO})_{2} \mathrm{Mn}(\mathrm{NCMe})$ with various donor ligands, ${ }^{39,40}$ we decided to use a similar approach for the preparation of 3. We have developed first an efficient preparation of $\mathrm{Cp}(\mathrm{CO})_{2} \mathrm{Mn}(\mathrm{NCMe})$ by simple UV irradiation of acetonitrile solution of cymantrene at room temperature, allowing to obtain the target product in $80 \%$ yield on the scale of ten grams after a simple crystallization. Though $\mathrm{Cp}(\mathrm{CO})_{2} \mathrm{Mn}(\mathrm{NCMe})$ is rather air-sensitive in solution, it can be easily handled in air in the solid state and stored under inert atmosphere for months without any decomposition. Gratifyingly, the addition of a catalytic amount of $1,1^{\prime}$ diacetylferrocenium tetrafluoroborate as oxidant to a solution of $\mathrm{Cp}(\mathrm{CO})_{2} \mathrm{Mn}(\mathrm{NCMe})$ and $\mathrm{PPh}_{2} \mathrm{H}$ in acetonitrile leads to the almost instantaneous formation of complex $\mathbf{3}$, isolated in $95 \%$ yield. Deprotonation of $\mathbf{3}$ by $n$-butyllithium, followed by the addition of $\mathrm{CS}_{2}$ and then alkylation by 1-bromoethylbenzene yields the desired Mn-RAFT agent 4 as a dark red oil in $81 \%$ yield (Scheme 1). In order to evaluate the reactivity of the Mn-RAFT agent, model polymerisations of St, $n$-BA and $N, N$ dimethylacrylamide (DMAAm) were performed at $60^{\circ} \mathrm{C}$ directly in NMR tubes with AIBN as thermal initiator using a [Monomer $]_{0} /[\mathrm{Mn}-\mathrm{RAFT}]_{0}$ ratio at about 200 and $\mathrm{C}_{6} \mathrm{D}_{6}$ as a solvent (Scheme 2, Table 1, entries 1-18). For each monomer, six parallel experiments were performed with variation of the polymerisation time. The initial reagent ratios (Table S1) were adjusted to obtain a theoretical number-average molar mass $\left(M_{\mathrm{nth}}\right)$ at complete monomer conversion of around $20 \mathrm{~kg} \mathrm{~mol}^{-}$ 1. Monomer conversions were determined by ${ }^{1} \mathrm{H} N M R$ spectroscopy based on the comparison of integral intensities of the vinylic protons of the monomers and those of 1,4-dioxane used as an internal standard (Fig. S7-S10). At the same time, ${ }^{31} \mathrm{P}\left\{{ }^{1} \mathrm{H}\right\} \mathrm{NMR}$ spectra were registered in the presence of triphenylphosphine sulphide $\mathrm{Ph}_{3} \mathrm{PS}$ as a chemical shift reference

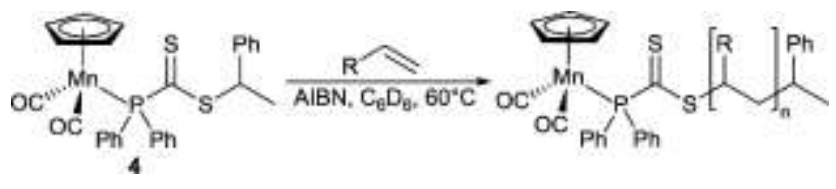

Scheme 2. Mn-RAFT mediated polymerisations. $\mathrm{R}=\mathrm{Ph}, \mathrm{CO}_{2} \mathrm{Bu}, \mathrm{CONMe}$. 
Table 1. Results of Mn-RAFT mediated polymerisations.

\begin{tabular}{|c|c|c|c|c|c|c|}
\hline Entry & $M$ & $\mathrm{t}, \mathrm{h}$ & conv. ${ }^{a}$ & $M_{\mathrm{nth}}{ }^{b}$ & $M_{\mathrm{n}}{ }^{c}$ & $\oplus^{d}$ \\
\hline 1 & St & 4 & $4 \%$ & 1150 & $\mathrm{ND}^{e}$ & $\mathrm{ND}^{e}$ \\
\hline 2 & St & 14 & $13 \%$ & 3100 & 2560 & 1.24 \\
\hline 3 & St & 24 & $21 \%$ & 4650 & 4600 & 1.30 \\
\hline 4 & St & 48 & $35 \%$ & 7350 & 7400 & 1.37 \\
\hline 5 & St & 72 & $51 \%$ & 10450 & 8700 & 1.37 \\
\hline 6 & St & 120 & $72 \%$ & 14550 & 11000 & 1.38 \\
\hline 7 & $n-\mathrm{BA}$ & 1 & $0 \%$ & 550 & $\mathrm{ND}^{e}$ & $\mathrm{ND}^{e}$ \\
\hline 8 & $n-B A$ & 2 & $1 \%$ & 750 & $\mathrm{ND}^{e}$ & $\mathrm{ND}^{e}$ \\
\hline 9 & $n-B A$ & 3 & $35 \%$ & 7350 & 6450 & 1.34 \\
\hline 10 & $n-B A$ & 5 & $53 \%$ & 10850 & 9600 & 1.27 \\
\hline 11 & $n$-BA & 8 & $73 \%$ & 14700 & 13050 & 1.26 \\
\hline 12 & $n$-BA & 24 & $90 \%$ & 18000 & 16400 & 1.26 \\
\hline 13 & DMAAm & 0.5 & $0 \%$ & 550 & $\mathrm{ND}^{e}$ & $\mathrm{ND}^{e}$ \\
\hline 14 & DMAAm & 0.75 & $1 \%$ & 750 & ND $e$ & $\mathrm{ND}^{e}$ \\
\hline 15 & DMAAm & 1 & $15 \%$ & 3450 & 2550 & 1.30 \\
\hline 16 & DMAAm & 1.5 & $38 \%$ & 7950 & 6950 & 1.30 \\
\hline 17 & DMAAm & 3 & $65 \%$ & 13200 & 12750 & 1.26 \\
\hline 18 & DMAAm & 6 & $85 \%$ & 17100 & 18450 & 1.28 \\
\hline 19 & St ${ }^{f}$ & 15 & $9 \%$ & 2250 & 2050 & 1.10 \\
\hline 20 & $n-\mathrm{BA}^{g}$ & 1 & $5 \%$ & 3150 & 3200 & 1.10 \\
\hline 21 & $n-\mathrm{BA}^{g}$ & 2 & $12 \%$ & 4750 & 4800 & 1.16 \\
\hline 22 & $n-\mathrm{BA}^{g}$ & 5 & $35 \%$ & 10050 & 9750 & 1.14 \\
\hline 23 & $n-\mathrm{BA}^{g}$ & 10 & $63 \%$ & 16500 & 16100 & 1.12 \\
\hline 24 & $n-\mathrm{BA}^{g}$ & 24 & $90 \%$ & 22700 & 22250 & 1.17 \\
\hline
\end{tabular}

${ }^{a}$ Monomer conversion, determined by ${ }^{1} \mathrm{H}$ NMR. ${ }^{b} M_{\mathrm{n}}$ th $=M_{\mathrm{w}}(\mathrm{Mn}-\mathrm{RAFT})+$ $\left([\mathrm{M}]_{0} /[\mathrm{Mn}-\mathrm{RAFT}]_{0}\right) \times($ conv. $) \times M_{\mathrm{w}}(\mathrm{M})$. Complete consumption of the CTA and a negligible contribution of the initiator-derived chains are assumed. ${ }^{c}$ Determined by SEC. ${ }^{d} \oslash=M_{\mathrm{w}} / M_{\mathrm{n}} .{ }^{e}$ Not determined. ${ }^{f}$ Preparation of macro RAFT agent PSt-MnRAFT. $g$ PSt-Mn-RAFT chain extension with $n$-BA.

that allowed qualitative evaluation of the RAFT agent transformation over the course of the polymerisation (Fig. S10S15, S17 and S18). Conversion-time data, number-average molar masses and dispersities of the obtained polymers are summarized in Table 1.

The ${ }^{31} \mathrm{P}$ NMR results are well correlated to previously reported data for other organophosphorus RAFT agents. ${ }^{23,24}$ Polymerisation of $n$-BA leads to the gradual disappearance of the singlet signal of the initial Mn-RAFT at $128.9 \mathrm{ppm}$ in the ${ }^{31} \mathrm{P}$ NMR spectrum with formation of a characteristic set of downfield signals in $129.0-130.5 \mathrm{ppm}$ range, corresponding to the phosphorus atom at the $\omega$-chain ends of $\mathrm{P}(n-\mathrm{BA})$ (Fig. 1, S11 and S14). The Mn-RAFT signal totally disappears after $3 \mathrm{~h}$ of polymerisation (35\% conversion), which indicates a high chain transfer constant to Mn-RAFT. One can also remark the appearance of a right-hand side shoulder on the Mn-RAFT signal after $1 \mathrm{~h}$, which initially increased and then totally disappeared after $3 \mathrm{~h}$. This signal may be associated with the formation of the Mn-RAFT/n-BA monoadduct during the RAFT preequilibrium. For PDMAAm, the transfer is even faster and ${ }^{31} \mathrm{P}$ NMR indicated complete RAFT agent consumption in less than $1 \mathrm{~h}$ of polymerisation, corresponding to $15 \%$ monomer conversion (Fig. S12 and S15). In the case of less reactive St (72\% of conversion after $120 \mathrm{~h}$, Fig. S7) Mn-RAFT is mostly consumed after $4 \mathrm{~h}$ of polymerisation (i.e. before $4 \%$ St conversion), leading in this case to new upfield signals corresponding to PStMn-RAFT (Fig. S10 and S13). It is important to note that in all

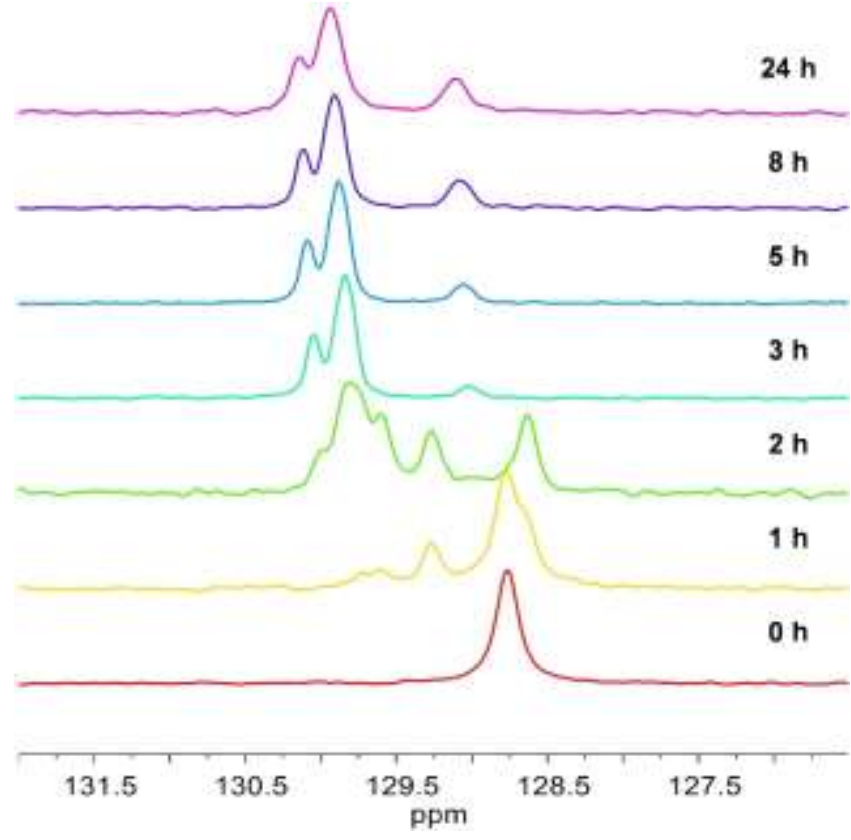

Fig. 1. ${ }^{31} \mathrm{P}\left\{{ }^{1} \mathrm{H}\right\}$ NMR evolution for $n$-BA polymerisation.

these cases no additional signals were detected on the entire 31P spectra, which is consistent with the fact that all the phosphorus atoms are part of the Mn-RAFT end-group even after a long reaction time.

Polymerisation of St exhibits the features of controlled chain growth with a linear increase of $M_{\mathrm{n}}$ with conversion and, initially, a good correlation between theoretically predicted

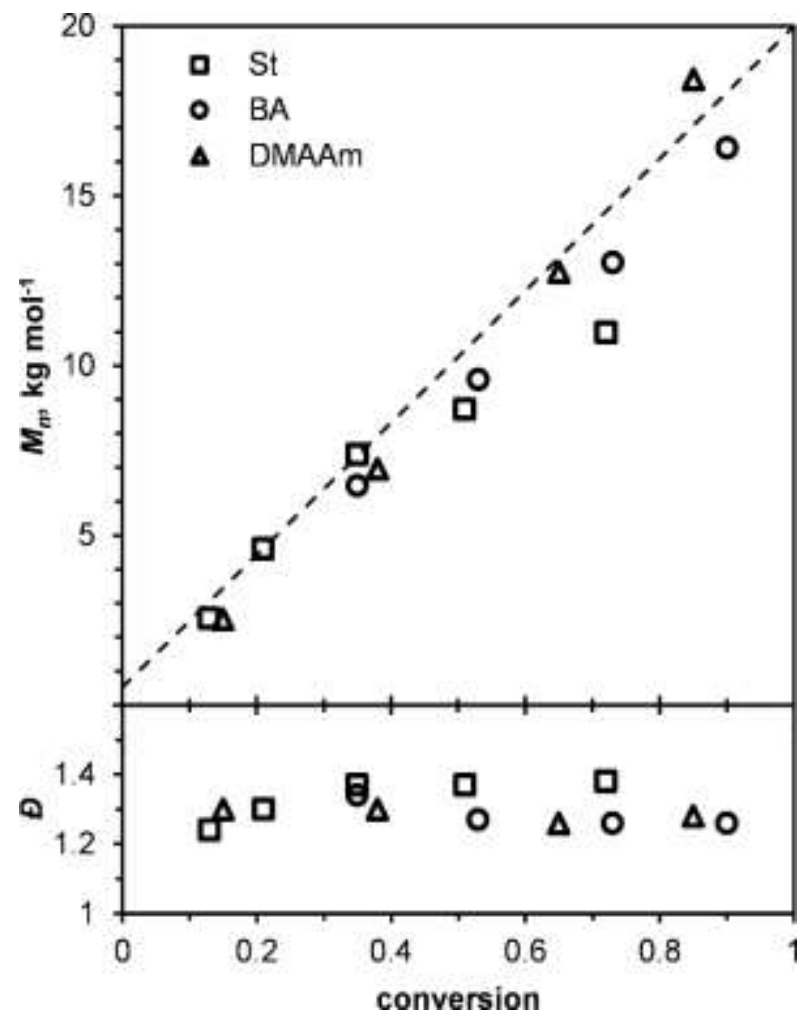

Fig. 2. Evolution of $M_{n}$ and $\Theta$ during Mn-RAFT polymerisations of St, $n$-BA and DMAAm. 


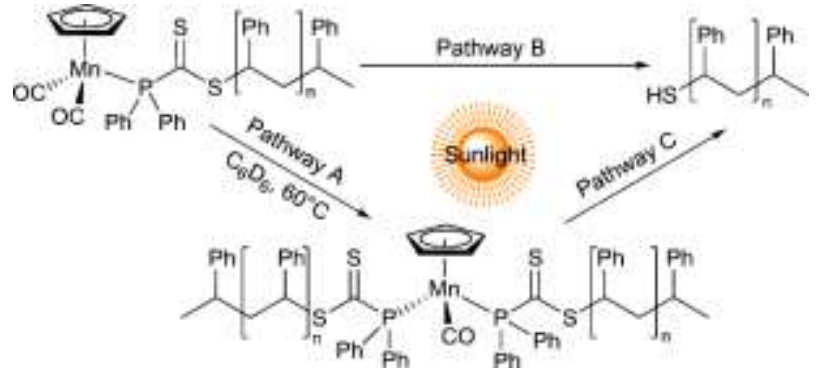

Scheme 3. Proposed mechanism for visible light degradation of Mn-RAFT terminated polymers. All pathways generate manganese and phosphorus side products.

values and the experimentally observed $M_{n}$ from the beginning of the reaction (Table 1, entries 1-6 and Fig. 2), similarly to what was observed for other metallo-phosphinocarbodithioates. ${ }^{24} \mathrm{~A}$ slight downward deviation was noticed in the $M_{\mathrm{n}}$ evolution profile at higher monomer conversion. Low dispersities were obtained early in the polymerisation (Table 1 , entry 2 , conv. = $13 \%, \oplus=1.24)$, but the values tended to increase with conversion. This could be due to the contribution of AIBNderived chains that are usually significant during RAFT polymerisation of St, as a result of the radical flux needed to take the reaction to high conversion. Here, the phenomenon was further illustrated by the appearance of a high molecular weight shoulder in SEC chromatograms (Fig. 3a) that is particularly pronounced. The peak molecular weight of this additional polymer population is approximately twice that of the main polymer distribution and its intensity is much higher than expected from classic radical termination. At the same time, this shoulder is visible with UV detection at $290 \mathrm{~nm}$ (Fig. S23), indicating the integrity of the thiocarbonylthio $\omega$-chain end, which was additionally confirmed by IR and ${ }^{31} \mathrm{P}$ NMR spectroscopy (vide infra). These observations may be explained by the photosensitivity of the Mn-RAFT chain end under visible light, which is well-documented for such manganese(I) phosphine complexes. ${ }^{41-43}$ Because of the long reaction times needed for St polymerisation, the polymer chain ends probably start to degrade over time, allowing chain coupling through the metal centre (Scheme 3, pathway A). To a lesser extent, we already observed a similar gradual loss of control with Mocarbonyl complexes in St polymerization for long reaction times. ${ }^{24}$ This is consistent with the fact that $\mathrm{Mn}$ and Mocarbonyl complexes are known to exhibit similar labilities, contrary to more stableCr and $\mathrm{W}$ counterparts. ${ }^{44}$

As expected, the $n$-BA polymerisation (Table 1, entries 7-12) required shorter reaction times than the St polymerization, because of the greater intrinsic reactivity of the acrylate monomers. This polymerisation also showed a linear increase of $M_{\mathrm{n}}$ with monomer conversion, matching the values predetermined by the monomer to agent ratio (Fig. 2). There is only a slight induction period ( $1 \%$ of conversion after $2 \mathrm{~h}$ of reaction, Table 1 , entry 8 ), probably due to the stability of the formed monoadduct intermediates, which have also been
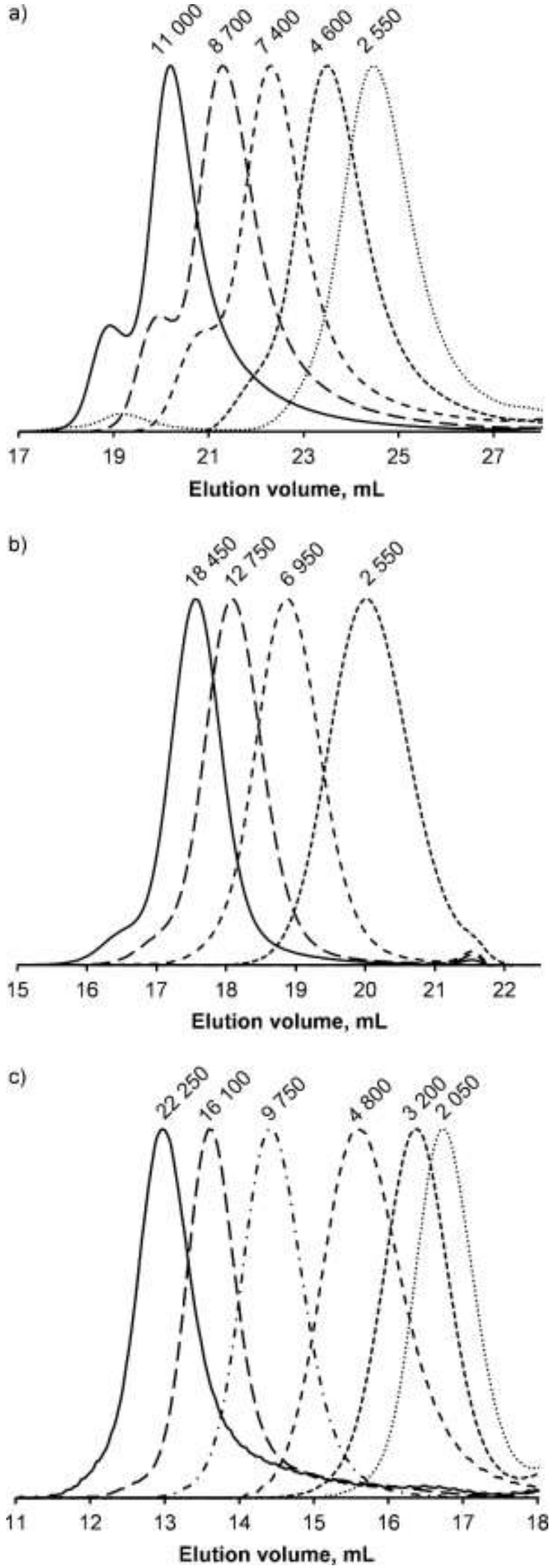

Fig. 3. Overlay of SEC chromatograms for Mn-RAFT polymerisation of (a) styrene , (b) DMAAm , (c) PSt-b-P( $n$-BA) . 
identified by ${ }^{31}$ P NMR spectroscopy (Fig. S14). The low $\oslash$ of the obtained polymers (less than 1.3, Table 1, entries 7-12 and Fig. 2) also demonstrate the efficiency of the Mn-RAFT agent for $n$ BA polymerisation. These characteristics of a controlled RAFT polymerisation are illustrated by the monomodal character of the SEC chromatograms of the P(n-BA) samples (Fig. S19).

The RAFT polymerisation of $\mathrm{N}, \mathrm{N}$-dimethylacrylamide (DMAAm) in the presence of Mn-RAFT was characterized by rapid monomer consumption (Table 1, entries 13-18) (65\% of DMAAm conversion after $3 \mathrm{~h}$ and $85 \% 3 \mathrm{~h}$ later). Similarly to $n$ BA, a short induction period was observed with only $1 \%$ of conversion after $45 \mathrm{~min}$ of reaction (Table 1, entry 14), which could also be correlated with the formation of low molar mass adducts (observed by ${ }^{31} \mathrm{P}$ NMR). The main peak that appears upfield at the beginning of the polymerisation was attributed to the monoadduct and to oligomers (Fig. S15). The $M_{\mathrm{n}}$ evolution with conversion is linear and perfectly correlated with the theoretical values (Fig. 2), which indicates nearly quantitative consumption of the Mn-RAFT agent. $\Theta$ values are in the 1.28 1.30 range (Table 1 , entries and $12-18$ and Fig. 2 ), similar to those observed for $\mathrm{P}(n-\mathrm{BA})$. The overlay of SEC chromatograms (Fig. $3 \mathrm{~b}$ ) indicates a good control of the polymerisation with monomodal molar mass distributions over the course of the polymerisation, although a small shoulder in the high molar mass area is visible at higher monomer conversion. Although much less pronounced than for St, this shoulder may be partly due to a fraction of dead chains generated from AIBN initiation. Also, other modes of coupling induced by visible light processes, as mentioned previously, cannot be ruled out.

To further demonstrate the controlled character of these polymerisations and the integrity of the polymer chain ends, we studied the block copolymerisation of St and $n$-BA (Table 1, entries 19-24). As was noticed during the homopolymerisations, the chain ends (especially with PSt) may be sensitive to visible light. Hence, the sequential polymerisations of St and $n$-BA were run in complete darkness. First, a low molar mass macro-RAFT agent was generated by polymerising St in toluene at $60^{\circ} \mathrm{C}$ (PSt4, $M_{\mathrm{n}}=2050 \mathrm{~g} \mathrm{~mol}^{-1}, \emptyset=1.10$, Table 1, entry 19). After purification, the resulting macro-RAFT agent provided efficient control for the AIBN-initiated polymerisation of $n$-BA (Table 1 , entries 20-24). Indeed, the $\mathrm{P}(n-\mathrm{BA})$ block grows with a linear increase of $M_{\mathrm{n}}$ in agreement with the theoretical values (Fig. $\mathrm{S} 20)$. There is no noticeable induction period in this case, even though the polymerisation is somewhat slower. After $2 \mathrm{~h}, 12 \%$ conversion is reached compared to only $1 \%$ for $n$-BA homopolymerisation (Table 1 , entries 21 and 8 respectively). In addition, dispersities are very low $(\theta=1.17$, conv. $=90 \%)$ with only a slight increase at high monomer conversion due to the contribution of dead chains from the initiator. Finally, the overlay of the SEC chromatograms presented in Fig. $3 c$ revealed monomodal polymer distributions and clear shifts towards lower retention times with $n$-BA conversion. Additionally, in contrast to SEC traces of $\mathrm{P}(n-\mathrm{BA}) \mathrm{s}$ synthesised without protection from light (Fig. S19), there is no shouldering visible in the higher molar mass area at high monomer conversion, thus corroborating our hypothesis on the key role of visible light for this coupling reaction.

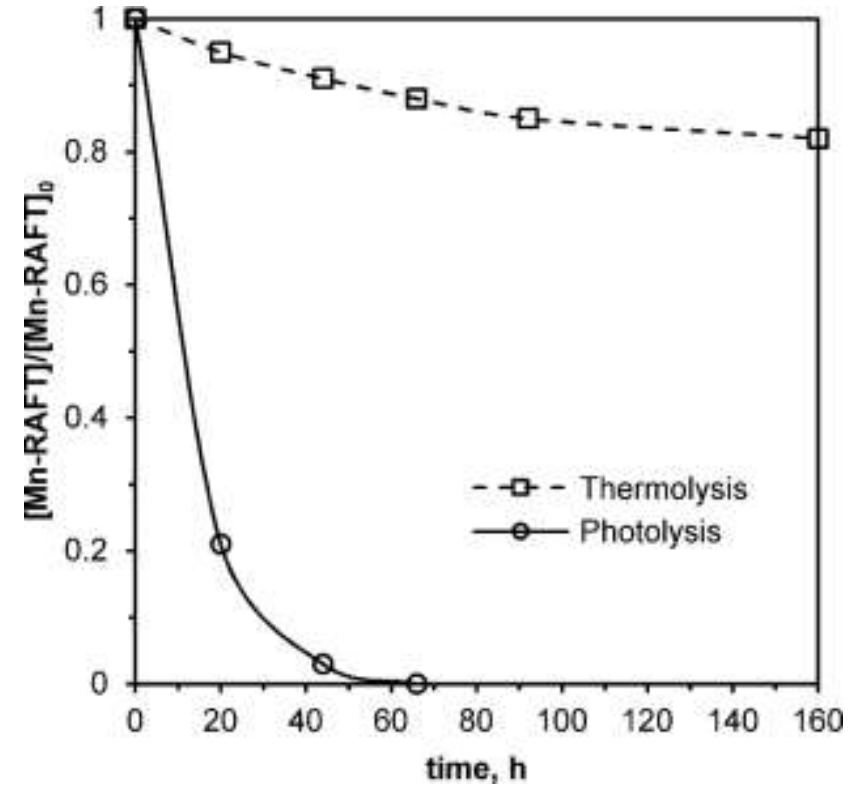

Fig. 4. Kinetic plots for thermal and photochemical degradation of Mn-RAFT.

${ }^{31} \mathrm{P}$ NMR monitoring also added key information about the polymerisation process. Besides confirming the nature of the PSt macro-RAFT (Fig. S17 and S18), it proved the switching efficiency of the macro-CTA toward $n$-BA polymerisation. Indeed, most of the PSt-Mn-RAFT was consumed after $1 \mathrm{~h}$ and its signals totally disappeared within $2 \mathrm{~h}$ (Fig. S18). The new upfield signals corresponding to the phosphorus atoms located at the $\omega$-chain ends of the $\mathrm{P}(n-\mathrm{BA})$ block keep the same general shape until the end of polymerisation and no additional peaks appear, proving high chain end fidelity.

To better understand the stability limits of Mn-RAFT, thermo- and photostability studies were monitored by ${ }^{31} \mathrm{P} N M R$. Solutions of Mn-RAFT in $\mathrm{C}_{6} \mathrm{D}_{6}$ with $\mathrm{Ph}_{3} \mathrm{PS}$ as internal standard were either thermostated at $60^{\circ} \mathrm{C}$ in the dark or exposed to sunlight at room temperature (Fig. 4, S21, S22). While only $18 \%$ of the compound degraded after $160 \mathrm{~h}$ of thermolysis in the dark, the decomposition in the presence of visible light was much faster reaching $79 \%$ after $20 \mathrm{~h}$ and $97 \%$ after $44 \mathrm{~h}$ (Fig. 4). Photolysis is accompanied by the disappearance of the deep red-violet colour of the Mn-RAFT and by the formation of a brown precipitate. After $20 \mathrm{~h}$ of irradiation, four new peaks were observed, two of which were assumed to belong to diphenylphosphine oxide ( $\delta 18.5$ ppm) and sulphide $(\delta 21.2$ $\mathrm{ppm}$, spectrum not shown). Subsequent disappearance of most of the phosphorus signals in ${ }^{31} \mathrm{P}$ NMR allowed us to conclude that insoluble organophosphorus species are formed.

The photostability of the Mn-RAFT-derived $\omega$-chain end was further studied using the PSt sample of Table 1, entry 4. 


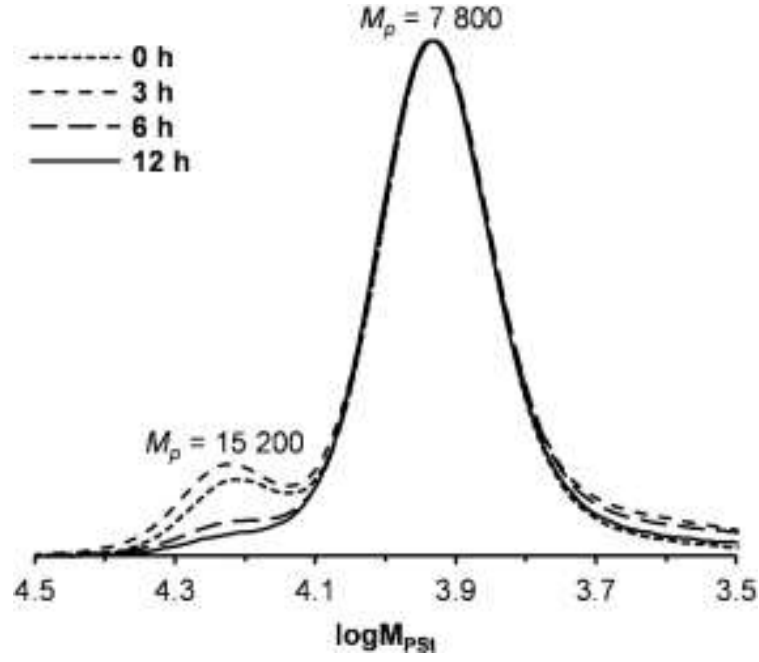

Fig. 5. Overlay of SEC chromatograms for the photolysis of PSt sample (7.4 kDa) with $\mathrm{dRI}$ detection.

Deconvolution of the SEC bimodal peak (Fig. 3a) shows that $M_{\mathrm{p}}$ of the two contributing distributions differ by a factor of two (7.8 and $15.2 \mathrm{~kg} \mathrm{~mol}^{-1}$ respectively). Visible-light irradiation led to a gradual discoloration of the solution with formation of a precipitate and SEC-RI showed the total disappearance of the high molecular weight shoulder (Fig. 5). During the photolysis monitored by SEC-UV (detector at $290 \mathrm{~nm}$ - Fig. S23- and 310 $\mathrm{nm}-$ Fig. S24), the intensity of this shoulder decreased after $3 \mathrm{~h}$. At the same time, UV detection at two different wavelengths revealed interesting trends (Fig. S25 and S26). First of all, the two different components of the bimodal distribution show different responses when the detector is set at $290 \mathrm{~nm}$ or at 310 $\mathrm{nm}$ (Fig. S25), which indicates that their absorption spectra are different. This shows that thiocarbonylthio fragments are present in both populations, but with different electronic environments. Detailed examination of the UV-SEC trace evolution as a function of photolysis time (Fig. S23 to S26) demonstrated that the main, low- $M_{\mathrm{n}}$ distribution decomposes much faster than the coupled species and the visible light absorption of both populations eventually disappears at the end of photolysis. Visible light irradiation allows cleavage of the Mn-RAFT moiety for both components through pathways $B$ and $C$ respectively, with restoration of a monomodal polymer distribution, as shown on Fig. 5. The same results were also obtained on the PSt sample having the main distribution centred at $M_{\mathrm{n}}=8.7 \mathrm{~kg} \mathrm{~mol}^{-1}$ and a second population with $M_{\mathrm{n}}$ of $17.4 \mathrm{~kg} \mathrm{~mol}^{-1}$ (Table 1, entry 5). Additional useful information about this photochemical demetallation process could be gathered by $I R$ and ${ }^{31} \mathrm{P}$ NMR spectroscopic studies. Unfortunately, the same sample shows only two $\mathrm{Mn}-\mathrm{CO}$ stretching vibrations in the IR spectrum at $1936 \mathrm{~cm}^{-1}$ and 1874 $\mathrm{cm}^{-1}$ (Fig. S27), with the same relative intensity of those of the starting Mn-RAFT (at $1929 \mathrm{~cm}^{-1}$ and $1853 \mathrm{~cm}^{-1}$, Fig. S28). Also, the ${ }^{31} \mathrm{P}$ NMR spectrum of the same polymer shows only one signal around $127.6 \mathrm{ppm}$ in the -50 to 300 ppm region (Fig. S29).

Similar spectroscopic signatures were observed for two low molecular mass PSt samples (Table 1 , entries 1 and 19) displaying a monomodal distribution with $M_{\mathrm{n}}$ of $1.0 \mathrm{~kg} \mathrm{~mol}^{-1}$ and $2.1 \mathrm{~kg} \mathrm{~mol}^{-1}$ : two $v_{\text {co }}$ bands in the IR spectra (1933 and 1870 $\mathrm{cm}^{-1}$, Fig. S30; 1940 and $1879 \mathrm{~cm}^{-1}$, Fig. S31; respectively) and broad signals in the ${ }^{31} \mathrm{P}$ NMR spectra at 127.4 (Fig. S32) and $128.2 \mathrm{ppm}$ (Fig. S33), respectively. The results of these different analyses are well correlated and consistent with the notion that the phosphoryl function is located at the chain end and is connected to both the thiocarbonylthio function and to the manganese atom. The distribution with doubled molar mass is not present in sufficient amount to be discriminated by these techniques. The signals generated by this component are probably hidden underneath those of the main component in both IR and ${ }^{31} \mathrm{P}$ NMR spectra, which leads us to postulate a closely related structure, as proposed in Scheme 3, with two polymers chains connected through the $\mathrm{CpMn}(\mathrm{CO})$ moiety. It is pertinent to point out that $\mathrm{CO}$ substitution for cymantrene derivatives are known to be almost exclusively promoted by visible light irradiation. 45

These two PSt samples $\left(M_{\mathrm{n}}=1.0 \mathrm{~kg} \mathrm{~mol}^{-1}\right.$ and $\left.2.1 \mathrm{~kg} \mathrm{~mol}^{-1}\right)$ were further investigated by carrying out the photobleaching with ${ }^{31 P}$ NMR monitoring. After 24 hours of visible light exposure at ambient temperature in THF, all the $\omega$-chain end resonance disappeared (Fig. S34). The kinetics of decomposition of the PSt with $M_{\mathrm{n}}$ of $1.0 \mathrm{~kg} \mathrm{~mol}^{-1}$ is slower, which is consistent with a comparatively higher concentration of Mn-RAFT group for this sample. Besides, the IR analysis of the product obtained from the $1.0 \mathrm{~kg} \mathrm{~mol}^{-1}$ sample (Fig. S35) clearly indicates the absence of the $v_{\mathrm{CO}}$ bands of the $\mathrm{Cp}(\mathrm{CO})_{2} \mathrm{Mn}$ moiety. Addition of water followed by filtration of the precipitated polymer led to efficient removal of the inorganic species with only diphenylphosphine oxide detected by ${ }^{31} \mathrm{P}$ NMR analysis.

The polymer obtained from photolysis of the $2.1 \mathrm{~kg} \mathrm{~mol}^{-1}$ PSt-Mn-RAFT sample was analysed by MALDI-TOF mass spectrometry. The major population found in the photolysed product is PSt with a sodium thiolate $\omega$-chain end (Fig. S36), using $\mathrm{Nal}$ as cationizing agent. However, the MS analysis performed on the initial PSt sample before photolysis led to the detection of the same PSt-SNa species (Fig. S37). When AgOTf was used instead of $\mathrm{Nal}$, again the Mn-RAFT end-group was cleaved off by the MALDI ionization process, only giving a $\mathrm{C}_{6} \mathrm{H}_{5}-$ $\mathrm{CH}=\mathrm{CH}$-terminated PSt (Fig. S38). In order to check that the obtained PSt-SNa after photolysis was not the consequence of the ionisation process, we performed a complete mass spectrometry study using the electron spray ionisation (ESI) technique. Although MALDI is considered to be a soft ionization technique, it involves higher energies than ESI and so generates more fragmentations, especially in the case of PSt chain-ends produced by RAFT. ${ }^{46}$ For this purpose, the PSt ${ }_{2.1 \mathrm{~K}-\mathrm{Mn} \text {-RAFT was }}$ analysed by ESI-MS and led before irradiation to the expected main population with both 1-phenylethyl and Mn-RAFT terminal groups (Fig. 6a), and after 2 days of sunlight exposure, to the thiolate- terminated PSt (Fig. 6b), likely generated from PSt-SH in presence of Nal. Thus, it appears that the visible lightinduced cleavage of the $\mathrm{Mn}-\mathrm{P}$ bond along with the destruction of the $\mathrm{Ph}_{2} \mathrm{P}-\mathrm{C}(=\mathrm{S}) \mathrm{S}-$ function, results in the formation of a PSt with $\mathrm{SH} \omega$-chain end along with side products such as diphenylphosphine oxide and water-soluble inorganic $\mathrm{Mn}$ containing species. Through these experiments using visible 
light, we found an elegant and facile way to remove $\mathrm{Mn}$ species from the polymer chain ends after polymerisation, while at the same time erasing possible chain defects caused by lightinduced chain coupling during polymerisation for prolonged reaction times. Our original approach adds up to the list of previously reported methods for the preparation of thiolterminated polymers from RAFT precursors, which usually employ reducing agents ${ }^{47}$ or nucleophiles like primary amines ${ }^{48}$ or sodium azide ${ }^{49}$.

\section{Conclusions}

A new manganese phosphinocarbodithioate (Mn-RAFT) was obtained by a three-step synthesis in good yield from industrially produced cymantrene and was fully characterized. Similarly to $\mathrm{Cr}$, Mo and $\mathrm{W}$ derivatives of the same kind, this compound proved to be an efficient RAFT agent for St, $n$-BA and DMAA polymerisations. In all cases, the polymerisations are characterized by a controlled chain growth with a linear increase of $M_{\mathrm{n}}$ with conversion and good correlation between experimental and theoretical $M_{n}$, with low dispersities throughout the polymerisation. The controlled character of these polymerisations and the integrity of the polymer chain ends were also evidenced by the synthesis of diblock copolymers of St and $n$-BA. ${ }^{31} \mathrm{P}$ NMR acted as a powerful tool for the monitoring of polymerisations and for highlighting the $\mathrm{Mn}$ RAFT reactivity, leading to fast formation of the phosphoruscapped polymer chains. The SEC analyses revealed, most significantly for PSt for long reaction times, the presence of a high molecular weight shoulder corresponding to a population with double molar mass. This phenomenon could not be ascribed only to classical termination by combination, and was rationalized by the formation of manganese bis(phosphine) complexes linking two polymer chains.

It was shown by ${ }^{31} \mathrm{P}$ NMR spectroscopy that Mn-RAFT is thermally stable but readily degrades under visible light. Hence, Mn-RAFT is an efficient reagent that is best used in the absence of light in case of long polymerisation times. However, even for samples that are contaminated by the side distribution of coupled chains, the activation of terminal and mid-chain $\mathrm{Mn}$ RAFT-fragments by visible light irradiation led to monomodal SH-terminated PSt, evidenced by ESI mass spectrometry and SEC. Taking into account the rich chemistry of the thiol group, this simple low-energy and chemical additive-free protocol for producing SH-ended polymers by RAFT may be useful for further derivatisations.

\section{Experimental Section}

General. All manipulations were carried out using Schlenk techniques under an atmosphere of dry argon. A liquid nitrogen/ethanol slush bath was used to maintain samples at the desired low temperature. All photochemical procedures were performed in a $125 \mathrm{~mL}$ reactor with an immersed $150 \mathrm{~W}$ $\mathrm{Hg}$ medium pressure lamp cooled by quartz jacket with circulating water. Chromatographic purification of the compounds was performed on silica (0.060-0.200 mm, $60 \AA$ A obtained from Acros Organics flushed with nitrogen just before use.

Solution IR spectra were recorded in $0.1 \mathrm{~mm} \mathrm{CaF}_{2}$ cells using a Perkin Elmer Frontier FT-IR spectrometer and given in $\mathrm{cm}^{-1}$ with relative intensity in parentheses. UV-Vis spectrum of $\mathbf{4}$ in $\mathrm{CH}_{2} \mathrm{Cl}_{2}$ was recorded on a Olis ${ }^{\circledR} \mathrm{HP}$ 8452A diode array spectrophotometer. ${ }^{1} \mathrm{H},{ }^{31} \mathrm{P}$, and ${ }^{13} \mathrm{C}$ NMR spectra were obtained on Bruker Avance 400 or Avance III HD 400 spectrometers at $400.2,162.0$ and $100.6 \mathrm{MHz}$, respectively and referenced to the residual signals of deuterated solvent ${ }^{50}\left({ }^{1} \mathrm{H}\right.$ and ${ }^{13} \mathrm{C}$ ) and to $85 \% \mathrm{H}_{3} \mathrm{PO}_{4}\left({ }^{31} \mathrm{P}\right.$ external standard). For all characterized compounds, the peak assignments in the ${ }^{1} \mathrm{H}$ and ${ }^{13} \mathrm{C}$ NMR spectra were based on COSY, HSQC and HMBC 2D experiments. High resolution mass spectra $\left(\mathrm{DCl}-\mathrm{CH}_{4}\right.$, positive mode) were obtained using GCT Premier (Waters) instrument. MALDI-TOF MS measurements were performed by using a MALDI Micro Mx (Waters) equipped with a nitrogen laser (337 $\mathrm{nm}, 4 \mathrm{~ns}$ pulse) and operated in reflectron mode. The matrix used was DCTB (trans-2-[3-(4-tert-butylphenyl)-2-methyl-2propenylidene] malononitrile) in presence of sodium iodide (Nal) or silver triflate (AgOTf). The ions were accelerated under a potential of $12 \mathrm{kV}$ and detected in positive mode. ESI-TOF Mass spectra were acquired with a QTOF Premier mass spectrometer (Waters) in electrospray ionization in positive mode. Samples of polystyrene were dissolved in chloroform, diluted at $1 / 10$ e with acetonitrile and then an acetone solution of $\mathrm{Nal}(10 \mathrm{mg} / \mathrm{mL})$ was added. The resulting samples are directly infused in the source. The source temperature and desolvatation temperature were $110^{\circ} \mathrm{C}$ and $200^{\circ} \mathrm{C}$ respectively, and the cone voltage was optimised at $10 \mathrm{~V}$. For both techniques, the acquisition software was Masslynx (Waters) and the spectra were processed by Polymerix 3.0 (Sierra Analytics).

NMR spectra of polymer samples were recorded using a Bruker Avance AMX 300 spectrometer with the operating frequencies of 300.1 and $121.5 \mathrm{MHz}$ for ${ }^{1} \mathrm{H}$ and ${ }^{31} \mathrm{P}$, respectively) at $25^{\circ} \mathrm{C}$. Chemical shifts are expressed in parts per million with 1,4-dioxane (3.35 ppm) and triphenylphosphine sulfide (42.1 ppm) as internal references for ${ }^{1} \mathrm{H}$ and ${ }^{31} \mathrm{P}\left\{{ }^{1} \mathrm{H}\right\} \mathrm{NMR}$ spectra, respectively.

The monomer conversions were determined by ${ }^{1} \mathrm{H}$ NMR spectroscopy. Number-average molar mass $\left(M_{n}\right)$ and dispersity $(\nexists)$ values of the polymer samples were determined by SEC. The SEC analyses of PSt and P( $n$-BA) were conducted on a system composed of Waters 515 HPLC pump, Agilent 1260 Autosampler, Varian ProStar 500 column valve module, set of three Waters columns (Styragel Guard Column, $20 \mu \mathrm{m}, 4.6 \mathrm{~mm}$ $\times 30 \mathrm{~mm}$, Styragel HR3, $5 \mu \mathrm{m}, 7.8 \mathrm{~mm} \times 300 \mathrm{~mm}$ and Styragel HR4E, $5 \mu \mathrm{m}, 7.8 \mathrm{~mm} \times 300 \mathrm{~mm}$ ), Varian ProStar 325 UV-Vis detector set at $290 \mathrm{~nm}$ and Wyatt Optilab rEX differential refractive index detector using tetrahydrofuran (THF) as an eluent at a flow rate of $1.0 \mathrm{~mL} \mathrm{~min}{ }^{-1}\left(35^{\circ} \mathrm{C}\right)$. The column system was calibrated with PSt standards (ranging from 0.860 to $483.400 \mathrm{~kg} \mathrm{~mol}^{-1}$ ) for PSt and PMMA standards (ranging from 1.120 to $\left.138.600 \mathrm{~kg} \mathrm{~mol}^{-1}\right)$ for $\mathrm{P}(n-\mathrm{BA})$ using the Landau-KuhnMark-Houwink-Sakurada equation. ${ }^{51}$ The SEC analyses of 
PDMAAm were carried out using a set of four Shodex columns(KD-G guard column, $20 \mu \mathrm{m}, 4.6 \mathrm{~mm} \times 30 \mathrm{~mm}$, KD-804, $7 \mu \mathrm{m}, 8 \mathrm{~mm} \times 300 \mathrm{~mm}, \mathrm{KD}-802.5,6 \mu \mathrm{m}, 8 \mathrm{~mm} \times 300 \mathrm{~mm}$, Shodex $\mathrm{KD}-805 \mathrm{~L}, 5 \mu \mathrm{m}, 8 \mathrm{~mm} \times 300 \mathrm{~mm})$ using DMF/LiBr $(10 \mathrm{mM})$ as an

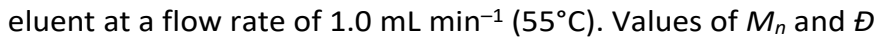
are reported using SEC-MALS data, $\mathrm{dn} / \mathrm{dc}=0.087 \mathrm{~mL} \mathrm{~g}^{-1} .527$ Prior to injection, samples were diluted to a concentration of 5 $\mathrm{mg} \mathrm{mL}^{-1}$ and filtered through $0.45 \mu \mathrm{m}$ Nylon syringe filters (THF) or $0.45 \mu \mathrm{m}$ PTFE syringe filters (DMF).

Materials. Dry and oxygen-free THF was obtained using LabSolv (Innovative Technology) solvent purification system. $\mathrm{CS}_{2}$ was dried over calcium hydride and distilled under argon prior to use. Acetonitrile was dried over $\mathrm{P}_{2} \mathrm{O}_{5}$ and distilled under argon prior to use. Hexane, heptane and toluene used for column chromatography purification were deoxygenated by nitrogen bubbling during 15-20 min. Deuterated chloroform used for NMR spectroscopy was filtered through a short column of basic alumina, degassed by three freeze-pump-thaw cycles and stored over molecular sieves (4Å). Technical quality cymantrene $\mathrm{CpMn}(\mathrm{CO})_{3}$ purchased as anti-knocking fuel additive in TPL Region Company (Moscow, Russia) was purified by recrystallization from hexane at $-20^{\circ} \mathrm{C}$ as previously described. ${ }^{53}$ Diacetylferrocenium tetrafluoroborate $\left(\left[\mathrm{Fc}^{\mathrm{Ac}}{ }_{2}\right] \mathrm{BF}_{4}\right)$ was prepared by known procedure. ${ }^{54}$ Styrene (St, Aldrich, 99\%), butyl acrylate ( $n$-BA, Aldrich, $99 \%$ ) and $N, N$-dimethylacrylamide (DMAAm, Aldrich, 99\%) were passed through a column filled with neutral aluminium oxide (Brockmann I) prior to use. 2,2'Azobis(2-methylpropionitrile) (AIBN, Acros, 98\%) was purified by double recrystallization from methanol. All other reagent grade chemicals purchased from commercial sources were used as received.

Synthesis of $\mathrm{Cp}(\mathrm{CO})_{2} \mathrm{Mn}$ (NCMe) (2). The solution of cymantrene 1 $(10.2 \mathrm{~g}, 50 \mathrm{mmol})$ in degassed $\mathrm{MeCN}(125 \mathrm{~mL})$ was irradiated with UV light under vigorous stirring and slow nitrogen bubbling through the solution. The photolysis was continued until the symmetric $v_{C O}$ band of cymantrene at $2020 \mathrm{~cm}^{-1}$ in the IR spectrum of the aliquot ceased to decrease (ca. $6 \mathrm{~h}$ ). The volatiles were evaporated under vacuum, the orange-brown residue was dissolved in a minimal amount of THF $(60-80 \mathrm{~mL})$ and the solution was filtered through Celite. Heptane $(100 \mathrm{~mL})$ was then added under stirring and the resulting solution was concentrated under vacuum to a half of the initial volume to induce the crystallization of the product which was completed at $-20^{\circ} \mathrm{C}$ overnight. The supernatant was removed by a cannula tipped with filter paper and the precipitate was washed with hexane $(2 \times 20 \mathrm{~mL})$ and dried to afford $\mathrm{Cp}(\mathrm{CO})_{2} \mathrm{Mn}(\mathrm{NCMe}) 2(8.7$ $\mathrm{g}, 80 \%)$, as orange-brown crystals. The combined supernatant and hexane washings were evaporated under vacuum to give a mixture of starting cymantrene and the product, which can be reused for the synthesis of $\mathrm{Cp}(\mathrm{CO})_{2} \mathrm{Mn}$ (NCMe). The analytical data were identical to that previously described. ${ }^{55}$

Synthesis of $\mathrm{Cp}(\mathrm{CO})_{2} \mathrm{Mn}\left(\mathrm{PPh}_{2} \mathrm{H}\right)$ (3). To an orange-brown solution of $\mathrm{Cp}(\mathrm{CO})_{2} \mathrm{Mn}(\mathrm{NCMe}) 2(4.34 \mathrm{~g}, 20.0 \mathrm{mmol})$ and $\mathrm{Ph}_{2} \mathrm{PH}(3.48 \mathrm{~mL}$, $20.0 \mathrm{mmol}$ ) in acetonitrile $(50 \mathrm{~mL})$ solid $\left[\mathrm{Fc}^{A c_{2}}\right] \mathrm{BF}_{4}(36 \mathrm{mg}, 0.1$ $\mathrm{mmol}$ ) was added at room temperature. The exothermic reaction started immediately, the colour of the solution changed to yellow-orange. After stirring for $10 \mathrm{~min}$ the IR spectrum of the solution showed the complete conversion of $\mathrm{Cp}(\mathrm{CO})_{2} \mathrm{Mn}(\mathrm{NCMe})$ into the complex 3. Acetonitrile was removed under reduced pressure and the resulting yelloworange oil was dissolved in toluene and filtered through a short silica column $(3 \times 8 \mathrm{~cm})$ with toluene as an eluent. The yellow eluate was evaporated under vacuum and the residue was thoroughly dried under vacuum to give complex 3 (6.88g, 95\%) as a yellow-orange oil.

${ }^{1} \mathrm{H}$ NMR (400.2 MHz, $\left.\mathrm{CDCl}_{3}, 298 \mathrm{~K}\right): 7.52-7.44(\mathrm{~m}, 4 \mathrm{H}, \mathrm{Ph}), 7.33-$ $7.24(\mathrm{~m}, 6 \mathrm{H}, \mathrm{Ph}), 6.80\left(\mathrm{~d},{ }^{1} \mathrm{~J}_{\mathrm{PH}}=297.0 \mathrm{~Hz}, 1 \mathrm{H}, \mathrm{PH}\right), 4.37\left(\mathrm{~d}, J_{\mathrm{PH}}=\right.$ $2.3 \mathrm{~Hz}, 5 \mathrm{H}, \mathrm{Cp}) ;{ }^{31} \mathrm{P}\left\{{ }^{1} \mathrm{H}\right\} \mathrm{NMR}\left(162.0 \mathrm{MHz}, \mathrm{CDCl}_{3}, 25^{\circ} \mathrm{C}\right): 69.4$ (br. s); ${ }^{13} \mathrm{C}\left\{{ }^{1} \mathrm{H}\right\}$ NMR $\left(100.6 \mathrm{MHz}, \mathrm{CDCl}_{3}, 25^{\circ} \mathrm{C}\right): 231.2$ (br. d, ${ }^{2} J_{\mathrm{PC}}=24.2$ $\mathrm{Hz}, \mathrm{Mn}-\mathrm{CO}), 136.0\left(\mathrm{~d},{ }^{1} \mathrm{JPC}_{\mathrm{PC}}=41.8 \mathrm{~Hz}, C_{\text {ipso }} \mathrm{PPh}_{2}\right), 132.1\left(\mathrm{~d},{ }^{2} \mathrm{~J}_{\mathrm{PC}}=\right.$ $10.0 \mathrm{~Hz}, \mathrm{CH}_{\text {ortho PPh }}$ ), $129.7\left(\mathrm{~d},{ }^{4} \mathrm{~J}_{\mathrm{PC}}=1.9 \mathrm{~Hz}, \mathrm{CH}_{\text {para PPh }}\right.$ ), 128.6 (d, ${ }^{3} J_{\mathrm{PC}}=9.5 \mathrm{~Hz}, \mathrm{CH}_{\text {meta }} \mathrm{PPh}_{2}$ ), $82.0(\mathrm{~s}, \mathrm{Cp})$.

Synthesis of $\mathrm{Cp}(\mathrm{CO})_{2} \mathrm{Mn}\left(\mathrm{PPh}_{2} \mathrm{CS}_{2} \mathrm{CH}(\mathrm{Me}) \mathrm{Ph}\right)$ (4). To a solution of $\mathrm{Cp}(\mathrm{CO})_{2} \mathrm{Mn}\left(\mathrm{PPh}_{2} \mathrm{H}\right) \mathbf{3}(1.90 \mathrm{~g}, 5.25 \mathrm{mmol})$ in THF $(50 \mathrm{~mL})$ a $1.6 \mathrm{M}$ solution $n$-BuLi in hexane $(3.8 \mathrm{~mL}, 6.1 \mathrm{mmol})$ was added dropwise at $-80^{\circ} \mathrm{C}$. The reaction mixture was allowed to warm to room temperature and stirred for one hour. Then the solution was cooled to $0^{\circ} \mathrm{C}$ and $\mathrm{CS}_{2}(4.81 \mathrm{~mL}, 80.0 \mathrm{mmol})$ was added via syringe. The resulting dark-red mixture was allowed to warm to room temperature and then was stirred for two hours. Finally, 1-bromoethylbenzene $(0.80 \mathrm{~mL}, 5.85 \mathrm{mmol})$ was added and the resulting mixture was stirred for $3 \mathrm{~h}$ and evaporated under vacuum. The crude product was purified by column chromatography on silica $(3 \times 20 \mathrm{~cm})$ under nitrogen atmosphere. Initial elution with hexane removed the excess of 1-bromoethylbenzene, followed by a large pink-red band of the product eluted with toluene/hexane 1:1 mixture. The evaporation of the eluate and drying of the residue under high vacuum afforded pure complex $4(2.31 \mathrm{~g}, 81 \%)$ as a pink-red oil. ${ }^{1} \mathrm{H}$ NMR $\left(400.2 \mathrm{MHz}, \mathrm{C}_{6} \mathrm{D}_{6}, 25^{\circ} \mathrm{C}\right): 7.80-7.74(\mathrm{~m}, 4 \mathrm{H}, \mathrm{Ph}), 7.13-$ $7.09(\mathrm{~m}, 2 \mathrm{H}, \mathrm{Ph}), 7.04-6.91(\mathrm{~m}, 9 \mathrm{H}, \mathrm{Ph}), 5.17\left(\mathrm{qd},{ }^{3} \mathrm{HHH}_{\mathrm{HH}}=7.1 \mathrm{~Hz}\right.$, $\left.{ }^{4} J_{\mathrm{PH}}=1.4 \mathrm{~Hz}, 1 \mathrm{H}, \mathrm{PhC}(H) \mathrm{CH}_{3}\right), 4.11\left(\mathrm{~d}, J_{\mathrm{PH}}=1.7 \mathrm{~Hz}, 5 \mathrm{H}, \mathrm{Cp}\right), 1.37$ $\left(\mathrm{dd},{ }^{3} J_{\mathrm{HH}}=7.1 \mathrm{~Hz},{ }^{5} \mathrm{JHH}_{\mathrm{PH}}=0.6 \mathrm{~Hz}, 3 \mathrm{H}, \mathrm{PhC}(\mathrm{H}) \mathrm{CH}_{3}\right) ;{ }^{31} \mathrm{P}\left\{{ }^{1} \mathrm{H}\right\} \mathrm{NMR}$ (162.0 MHz, $\mathrm{C}_{6} \mathrm{D}_{6}, 25^{\circ} \mathrm{C}$ ): 128.9 (s); ${ }^{13} \mathrm{C}\left\{{ }^{1} \mathrm{H}\right\} \mathrm{NMR}(100.6 \mathrm{MHz}$, $\left.\mathrm{C}_{6} \mathrm{D}_{6}, 25^{\circ} \mathrm{C}\right): 241.6\left(\mathrm{~d},{ }^{1} \mathrm{~J}_{\mathrm{PC}}=2.8 \mathrm{~Hz}, \mathrm{PCS}_{2}\right), 232.3$ (br. d, ${ }^{2} J_{\mathrm{PC}}=21.6$ $\mathrm{Hz}, \mathrm{Mn}-\mathrm{CO}$ ), $141.2\left(\mathrm{~s}, \mathrm{C}_{\text {ipso }} P h C(\mathrm{H}) \mathrm{CH}_{3}\right), 137.3\left(\mathrm{~d},{ }^{1} J_{\mathrm{PC}}=20.7 \mathrm{~Hz}\right.$, $\left.\mathrm{C}_{\text {ipso PPh }}\right), 136.9\left(\mathrm{~d},{ }^{1} \mathrm{JPC}_{\mathrm{PC}}=20.5 \mathrm{~Hz}, \mathrm{C}_{\text {ipso }} \mathrm{PPh}_{2}\right), 134.3\left(\mathrm{~d},{ }^{2} \mathrm{JPC}_{\mathrm{PC}}=10.5\right.$ $\mathrm{Hz}, \mathrm{CH}_{\text {ortho PPh }}$ ), 134.1 (d, ${ }^{2} J_{\mathrm{PC}}=11.1 \mathrm{~Hz}, \mathrm{CH}_{\text {ortho }} \mathrm{PPh}_{2}$ ), 130.3 (br. d, ${ }^{4} J_{\mathrm{PC}}=2.0 \mathrm{~Hz}, \mathrm{CH}_{\text {para } \mathrm{PPh}}$ ), 130.25 (br. d, ${ }^{4} \mathrm{~J}_{\mathrm{PC}}=1.9 \mathrm{~Hz}, \mathrm{CH}_{\text {para } \mathrm{PPh}_{2}}$ ), 128.7, 128.4, $128.3\left(\mathrm{~s}, \mathrm{CH}_{\mathrm{Ph}}\right), 128.2\left(\mathrm{~d},{ }^{3} \mathrm{~J}_{\mathrm{PC}}=9.3 \mathrm{~Hz}, \mathrm{CH}_{\text {meta } \mathrm{PPh}_{2}}\right)$, 83.7 (s, $\mathrm{Cp}$ ), 50.5 (s, $\left.\left.\mathrm{PhC}(\mathrm{H}) \mathrm{CH}_{3}\right), 20.4 \mathrm{PhC}(\mathrm{H}) \mathrm{CH}_{3}\right)$. IR (THF): $\mathrm{v}_{\mathrm{CO}}$ 1940.5 (s), $1880.5 \mathrm{~cm}^{-1}$ (s). HRMS ( $\mathrm{DCl}-\mathrm{CH}_{4}$, positive mode) $\mathrm{m} / \mathrm{z}$ : 542.0281 (100\%), calcd. for $\mathrm{C}_{28} \mathrm{H}_{24} \mathrm{MnO}_{2} \mathrm{PS}_{2}$ (M): 542.0336. UVVis $\left(\mathrm{CH}_{2} \mathrm{Cl}_{2}\right.$, Fig. S39) $\lambda \mathrm{nm}(\varepsilon) 460$ (600); 560 (700).

General polymerisation procedure. The solution $(5 \mathrm{~mL})$ that contained the monomer, RAFT agent (or PSt-Mn-RAFT agent, in case of block copolymerization with $n$-BA), AIBN, 1,4-dioxane and triphenylphosphine sulfide in $\mathrm{C}_{6} \mathrm{D}_{6}$ (see Table S1) was prepared in $15 \mathrm{~mL}$ Schlenk tube with PTFE needle valve and degassed by three freeze-pump-thaw cycles. Then solution was transferred into 6 amber NMR tubes in the glovebox under argon atmosphere and sealed with rubber septa. Tubes were heated at $60^{\circ} \mathrm{C}$ in a thermostated heating block for the requisite times. Polymerisation was quenched by freezing in liquid 
nitrogen and the obtained solution was analyzed with NMR. Then the excess amount of monomer and solvent were removed by evaporation at ambient temperature under vacuum and the residues were analysed using SEC.

General photolysis procedure for Mn-RAFT and RAFT polymers.

$30 \mathrm{mg}$ of polymer sample with Mn-RAFT $\omega$-chain end were dissolved in $2 \mathrm{~mL}$ of THF (or $\mathrm{CDCl}_{3}$ ). The resulting solutions were placed in $5 \mathrm{~mL}$ screw cap vial and exposed to sunlight at ambient temperature. The evolution of the photolysis was visually followed by the bleaching of the initial deep red-violet solution as well as the decrease of the corresponding peak in ${ }^{31} \mathrm{P} N M R$, in the case of $\mathrm{CDCl}_{3}$ solutions. Reactions were completed after $44 \mathrm{~h}$ of exposure. The solutions were analysed directly by MALDI-TOF and ESI mass spectrometry, and by ${ }^{31} \mathrm{P}$ NMR spectroscopy. For IR analysis the resulting mixtures were first diluted with water and filtered and the precipitated polymers were air-dried.

\section{Conflicts of interest}

There are no conflicts to declare.

\section{Acknowledgements}

The authors thank the "Agence Nationale de la Recherche" (ANR) for the RAFTSWITCH grant (http://www.agencenationale-recherche.fr).

\section{References}

1 G. Moad, E. Rizzardo and S. H. Thang, Aust. J. Chem., 2012, 65, 985-1076

2 J. Chiefari, R. T. A. Mayadunne, C. L. Moad, G. Moad, E. Rizzardo, A. Postma and S. H. Thang, Macromolecules, 2003, 36, 2273-2283.

3 Y. K. Chong, J. Krstina, T. P. T. Le, G. Moad, A. Postma, E. Rizzardo and S. H. Thang, Macromolecules, 2003, 36, 22562272.

$4 \quad$ M. Destarac, Polym. Rev., 2011, 51, 163-187.

5 J. Chiefari, Y. K. B. Chong, F. Ercole, J. Krstina, J. Jeffery, T. P. T. Le, R. T. A. Mayadunne, G. F. Meijs, C. L. Moad, G. Moad, E. Rizzardo, S. H. Thang and C. South, Macromolecules, 1998, 31, 5559-5562.

6 R. T. A. Mayadunne, E. Rizzardo, J. Chiefari, Y. K. Chong, G. Moad and S. H. Thang, Macromolecules, 1999, 32, 69776980.

7 M. Destarac, D. Charmot, X. Franck and S. Z. Zard, Macromol. Rapid Commun., 2000, 21, 1035-1039.

$8 \quad$ M. Destarac, W. Bzducha, D. Taton, I. Gauthier-Gillaizeau and S. Z. Zard, Macromol. Rapid Commun., 2002, 23, 10491054.

9 M. Destarac, C. Brochon, J. M. Catala, A. Wilczewska and S. Z. Zard, Macromol. Chem. Phys., 2002, 203, 2281-2289.

10 M. Benaglia, J. Chiefari, Y. K. Chong, G. Moad, E. Rizzardo and S. H. Thang, J. Am. Chem. Soc., 2009, 131, 6914-6915. D. J. Keddie, C. Guerrero-Sanchez, G. Moad, E. Rizzardo and
S. H. Thang, Macromolecules, 2011, 44, 6738-6745.

G. Moad, D. Keddie, C. Guerrero-Sanchez, E. Rizzardo and S. H. Thang, Macromol. Symp., 2015, 350, 34-42.

J. Gardiner, I. Martinez-Botella, J. Tsanaktsidis and G. Moad, Polym. Chem., 2016, 7, 481-492.

J. Gardiner, I. Martinez-Botella, T. M. Kohl, J. Krstina, G. Moad, J. H. Tyrell, M. L. Coote and J. Tsanaktsidis, Polym. Int., 2017, 66, 1438-1447.

E. Girard, T. Tassaing, J. D. Marty and M. Destarac, Polym. Chem., 2011, 2, 2222-2230.

2013, 66, 1564-1569.

Destarac and C. Mingotaud, Chem. Mater., 2010, 22, 37123724.

A. Guinaudeau, O. Coutelier, A. Sandeau, S. Mazières, H. D. Nguyen Thi, V. Le Drogo, D. J. Wilson and M. Destarac, Macromolecules, 2014, 47, 41-50.

I. Kulai, O. Brusylovets, Z. Voitenko, S. Harrisson, S. Mazières and M. Destarac, ACS Macro Lett., 2015, 4, 809813.
I. Kulai, N. Saffon-Merceron, Z. Voitenko, S. Mazières and M. Destarac, Chem. - A Eur. J., 2017, 23, 16066-16077. A. Alberti, M. Benaglia, M. Laus, D. Macciantelli and K. Sparnacci, Macromolecules, 2003, 36, 736-740. M. Laus, R. Papa, K. Sparnacci, A. Alberti, M. Benaglia and D. Macciantelli, Macromolecules, 2001, 34, 7269-7275.

S. Mazières, I. Kulai, R. Geagea, S. Ladeira and M. Destarac, Chem. - A Eur. J., 2015, 21, 1726-1734.

R. Geagea, S. Ladeira, S. Mazières and M. Destarac, Chem. A Eur. J., 2011, 17, 3718-3725.

M. Destarac, Macromol. React. Eng., 2010, 4, 165-179.

G. Moad, E. Rizzardo and S. H. Thang, Polym. Int., 2011, 60, 9-25.

S. Shanmugam, J. Xu and C. Boyer, Macromol. Rapid Commun., 2017, 38, 1-40.

T. G. McKenzie, Q. Fu, M. Uchiyama, K. Satoh, J. Xu, C. Boyer, M. Kamigaito and G. G. Qiao, Adv. Sci., 2016, 3, 1-9. C. Fu, Z. Huang, C. J. Hawker, G. Moad, J. Xu and C. Boyer, Polym. Chem., 2017, 8, 4637-4643.

K. Jung, C. Boyer and P. B. Zetterlund, Polym. Chem., 2017, 8, 3965-3970.

R. N. Carmean, C. A. Figg, G. M. Scheutz, T. Kubo and B. S. Sumerlin, ACS Macro Lett., 2017, 6, 185-189.

K. Koumura, K. Satoh, M. Kamigaito, Polym. J. 2009, 41, 595603.

M. Höfler, H. Hausmann and W. Saal, Zeitschrift für Naturforsch. B, 1976, 31, 790-794.

H. Schumann, O. Stelzer, J. Kuhlmey and U. Niederreuther, J. Organomet. Chem., 1971, 28, 105-113.

H. Lang, G. Mohr, O. Scheidsteger and G. Huttner, Chem. Ber., 1985, 118, 574-596.

Z. Pang, T. J. Burkey and R. F. Johnston, Organometallics, 1997, 16, 120-123.

C. I. Pongor, Z. Gengeliczki, L. Szepes, F. Axe and B. Sztáray, Organometallics, 2010, 29, 724-731.

38 D. A. Valyaev, S. Bastin, K. I. Utegenov, N. Lugan, G. Lavigne 
and N. A. Ustynyuk, Chem. - A Eur. J., 2014, 20, 2175-2178.

39 J. W. Hershberger and J. K. Kochi, J. Chem. Soc. Chem. Commun., 1982, 212-214.

40 J. W. Hershberger, R. J. Klingler and J. K. Kochi, J. Am. Chem. Soc., 1983, 105, 61-73.

41 A. A. Sorensen and G. K. Yang, J. Am. Chem. Soc., 1991, 113, 7061-7063. T. T. To, C. E. Barnes and T. J. Burkey, Organometallics, 2004, 23, 2708-2714.

43 E. Subasi, O. S. Senturk and F. Ugur, Transit. Met. Chem., 2004, 29, 649-652.

44 R. H. Crabtree, The Organometallic Chemistry of the Transition Metals, Wiley-Interscience, 4th edition, New York, 2005.

A. G. Ginzburg, Russ. Chem. Rev., 2009, 78, 195-210.

C. Ladavière, P. Lacroix-Desmazes and F. Delolme, Macromolecules, 2009, 42, 70-84.
A.B. Lowe, B.S. Sumerlin, M.S. Donovan, C.L. McCormick, J.
Am. Chem. Soc. 2002, 124, 11562-11563

M.Li, P. De, H. Li, B. Sumerlin, Polym. Chem. 2010, 1, 854859.

Y. Wu, Y. Zhou, J. Zhu, W. Zhang, X. Pan, Z. Zhang, X. Zhu, Polym. Chem. 2014, 5, 5546-5550.

H. E. Gottlieb, V. Kotlyar and A. Nudelman, J. Org. Chem., 1997, 62, 7512-7515.

T. Gruendling, T. Junkers, M. Guilhaus and C. BarnerKowollik, Macromol. Chem. Phys., 2010, 211, 520-528. E. Read, A. Guinaudeau, D. James Wilson, A. Cadix, F. Violleau and M. Destarac, Polym. Chem., 2014, 5, 2202. D. A. Valyaev, M. A. Uvarova, A. A. Grineva, V. César, S. N. Nefedov and N. Lugan, Dalt. Trans., 2016, 45, 1195311957.

C. Guillon and P. Vierling, J. Organomet. Chem., 1994, 464, C42-C44. 3896-3908. 